\title{
FAKTOR-FAKTOR YANG BERHUBUNGAN DENGAN TINGKAT PARTISIPASI ANGGOTA KOPERASI (Kasus pada KUD Tenera Jaya Di Desa Banjar Panjang Kecamatan Kerumutan Kabupaten Pelalawan dan Koperasi Bina Usaha Desa Benayah Kecamatan Pusako Kabupaten Siak Provinsi Riau)
}

\author{
FACTORS RELATED TO PARTICIPATION LEVEL OF COOPERATIVE \\ MEMBERS (Case in KUD Tenera Jaya in Banjar Panjang Village, Kerumutan \\ District, Pelalawan Regency and Bina Usaha Cooperative, Benayah Village, Pusako \\ District, Siak Regency, Riau Province)
}

\author{
Marliati Ahmad, Rila Afandi dan Dewi Nurmala \\ Program Studi Agribisnis Fakultas Pertanian Universitas Islam Riau \\ Jl. Kaharuddin Nasution No. 113 Pekanbaru 28284 \\ E-mail: marliatiahmad@agr.uir.ac.id
}

\begin{abstract}
Cooperation is a profit-oriented and family-based social organization which aim to help in increasing the budget. This study aims to analyze: characteristics of management, employees and members of the Cooperation, factors related to the level of cooperation member participation. This research was carried out at the KUD Tenera Jaya, Banjar Panjang Village, Kerumutuan District, Pelalawan Regency and Bina Usaha Cooperative in Benayah Village, Pusako District, Siak Regency, Riau Province, during 6 months. The method used in this study is a survey method. The respondents consisted of members, management and employees. Management and Employee Respondents were taken in a census, that is, 3 cooperatives and 3 employees' cooperatives. Respondents from the Tenera Jaya Cooperative were taken by cluster sampling, 44 were taken from 370 people. Samples of members of the Cooperative Business Development taken by stratified sampling are 60 people out of 210 people. Data were analyzed descriptively qualitative and quantitative descriptive appraloch. The results of the study were average of management age 51 years, employees of 35 years and 49.81 years. The average level of education of administrators was 10.5 years (not graduated from high school), 11.5 years employees (graduated from high school) and 8.45 years (equivalent to junior high school). The education level of management, employees and members of the cooperation was relatively low. The average business experience of management was 10.06 years, employees were 10.33 years, and members were 12.45 years. The average amount of income from the management of palm oil was $\mathrm{Rp} 2.6$ million per month, employees were $\mathrm{Rp} 2.28$ million per month and members were Rp. 2.99 million per month. The average number of family management dependents was 3 people, 2 employees and 3 members. Tenera Jaya cooperative business performance can be seen from the Value of Direct Economic Benefits and economic efficiency analysis. The level of overall participation of KUD Tenera Jaya members (participation in decision making in organizations, participation in the implementation of cooperative activities and services, participation in evaluating cooperative programs, participation in rights and obligations as members) received good category scores. The business performance of the Bina Usaha Cooperation was in the good category. The level of member participation in Bina Usaha cooperation was also a good category. Factors that significantly related to the level of farmer participation were the Cooperative Bina Usaha Performance and the experience of being a KUD member. While the other characteristic factors did not significantly related. This means that the better the cooperative's business performance is felt by members and the more the level of member participation in the cooperative increases. In addition, the more experienced being a member of a cooperation is the better the level of participation of cooperation members.
\end{abstract}

Keyword: Cooperative, Business Performance, Participation Level of Cooperative Members 


\begin{abstract}
ABSTRAK
Koperasi merupakan sebuah organisasi social ekonomi yang berorientasi profit dan berasaskan kekeluargaan dengan tujuan membantu meningkatkan perekonomian rakyat, Penelitian ini bertujuan untuk menganalisis karakteristik pengurus, karyawan dan anggota Koperasi, kinerja usaha dan tingkat partisipasi anggota dan faktor-faktor yang berhubungan dengan tingkat partisipasi anggota koperasi. Penelitian ini dilaksanakan di KUD Tenera Jaya Desa Banjar Panjang Kecamatan Kerumutuan Kabupaten Pelalawan dan pada Koperasi Bina Usaha di Desa Benayah Kecamatan Pusako Kabupaten Siak Provinsi Riau selama 6 bulan. Metode yang digunakan dalam penelitian ini adalah survei. Responden penelitian terdiri dari anggota, pengurus dan karyawan, Responden pengurus dan karyawan diambil secara sensus, yaitu berjumlah 3 pengurus dan 3 karyawan. Responden anggota Koperasi Tenera Jaya diambil secara cluster Sampling berjumlah 44 orang dari 370 orang. Sampel anggota pada Koperasi Bina Usaha diambil secara stratified sampling yaitu 60 orang dari 210 orang. Data dianalisis secara deskriptif kualitatif dan deskriptif kuantitatif. Hasil penelitian menunjukkan rataan umur pengurus 51 tahun, karyawan 35 tahun dan anggota 49,81 tahun. Rata-rata tingkat pendidikan pengurus 10,5 tahun (tidak tamat SLTA), karyawan 11,5 tahun (tamat SLTA) dan anggota 8,45 tahun (setara SLTP). Tingkat pendidikan pengurus, karyawan dan aggota koperasi tergolong rendah. Rata-rata pengalaman berusaha pengurus 10,06 tahun, karyawan 10,33 tahun, dan anggota 12,45 tahun. Rata-rata jumlah pendapatan dari kelapa sawit pengurus $\mathrm{Rp}$ 2,6 juta perbulan, karyawan Rp 2,28 juta perbulan dan anggota $\mathrm{Rp} 2,99$ juta perbulan. Jumlah tanggungan keluarga pengurus rata-rata 3 orang, karyawan 2 orang dan anggota 3 orang. Kinerja usaha koperasi Tenera Jaya dilihat dari Nilai Manfaat Ekonomi Langsung dan analisis efisiensi ekonomi termasuk kategori baik. Tingkat partisipasi anggota KUD Tenera Jaya (partisipasi pengambilan keputusan dalam organisasi, partisipasi pelaksanaan kegiatan dan pelayanan koperasi, partisipasi evaluasi program koperasi, partisipasi hak dan kewajiban sebagai anggota) keseluruhannya memperoleh nilai kategori baik. Kinerja usaha pada Koperasi Bina Usaha termasuk kategori baik. Tingkat partisipasi anggota pada koperasi Bina Usaha juga kategori baik. Faktorfaktor yang berhubungan signifikan dengan tingkat partisipasi petani adalah Kinerja Usaha Koperasi dan pengalaman menjadi anggota KUD. Sedangkan factor-faktor karakteristik yang lain tidak berhubungan signifikan. Artinya, semakin baik kinerja usaha koperasi yang dirasakan anggota, maka semakin meningkat tingkat partisipasi anggota terhadap koperasi. Selain itu, semakin berpengalaman menjadi anggota koperasi semakin baik tingkat partisipasi anggota koperasi.
\end{abstract}

Keyword: Koperasi, Kinerja Usaha, Tingkat Partisipasi Anggota Koperasi

\section{PENDAHULUAN}

\section{Latar Belakang}

Koperasi sesuai dengan amanat Undangundang dasar 1945 adalah soko guru perekonomian Indonesia. Perekonomian Indonesia disusun sebagai usaha Bersama dan berasas kekeluargaan. Ini maknanya, perekonomian Indonesia pelaku utamanya seharusnya adalah koperasi. Bagaimana kenyataannya, apakah koperasi telah menjadi pelaku utama perekonomian dalam bidang pertanian?

Koperasi adalah salah satu organisasi yang memiliki peran ganda yaitu sebagai organisasi social dan sekaligus organisasi ekonomi. Apakah koperasi petani kita sudah menjalankan kedua peran tersebut

Salah satu hubungan penting yang harus dilakukan koperasi adalah dengan para anggotanya (agar anggota berpartsipasi), yang kedudukannya sebagai pemilik sekaligus pengguna jasa koperasi. Motivasi ekonomi anggota sebagai pemilik akan mempersoalkan dana (simpanan-simpanan) yang telah diserahkannya, apakah menguntungkan atau tidak. Sedangkan anggota sebagai pengguna akan mempersoalan kontinuitas pemasaran produknya, pengadaan kebutuhan barang dan jasa, menguntungkan atau tidaknya pelayanan koperasi dibandingkan penjual atau pembeli di luar koperasi. 
Partisipasi yang berasal dari bahasa Inggris participation, menurut OXFORD Advanced Learner's Dictionary, 1994 berarti (action of) participating in some thing; Union leaders called for the active participation of all members in the day of protest. Dengan demikian partisipasi adalah perbuatan atau keterlibatan anggota dalam kegiatan tertentu. Akan sangat berat jika pemimpin koperasi bekerja sendiri tanpa dukungan partisipasi anggota atau bawahan.

Hanel (1989) ada beberapa hal yang dapat merangsang anggota untuk berpartisipasi dalam koperasi: Adanya pelayanan yang efisien. Sejauh mana intensitas rangsangan yang dikehendaki anggota sangat tergantung pada beberapa pertimbangan;

a. Dapat memenuhi kebutuhan mereka secara pribadi sehingga dapat meningkatkan perbaikan rumah tangganya, unit usahanya.

b. Bahwa anggota akan mendapatkan barang atau jasa yang memang tidak tersedia di pasar, tetapi hanya tersedia di perusahaan koperasi.

c. Disediakan dengan harga yang lebih murah dan kualitas yang lebih baik dibandingkan dengan di luar koperasi

Partisipasi anggota menentukan keberhasilan koperasi. Sedangkan tingkat partisipasi anggota dipengaruhi oleh beberapa faktor yaitu besarnya nilai manfaat pelayanan koperasi secara utilitarian maupun normatif. Motivasi utilitarian sejalan dengan kemanfaatan ekonomis. Kemanfaatan ekonomis yang dimaksud adalah insentif berupa pelayanan barang-jasa oleh perusahaan koperasi yang efisien, atau adanya pengurangan biaya dan atau diperolehnya harga yang menguntungkan serta penerimaan bagian dari keuntungan (SHU) baik secara tunai maupun dalam bentuk barang.

\section{Perumusan Masalah}

Bagaimana dengan koperasi petani ? Dalam hal ini koperasi petani kelapa sawit kasus pada: KUD Tenera Jaya Di Desa Banjar Panjang Kecamatan Kerumutan Kabupaten Pelalawan dan Koperasi Bina Usaha Desa Benayah Kecamatan Pusako Kabupaten Siak Provinsi Riau? Perumusan masalah penelitian ini adalah:
1. Bagaimana karakteristik pengurus, karyawan dan anggota koperasi?

2. Bagaimana kinerja usaha dan tingkat partisipasi anggota koperasi?

3. Faktor-faktor apa sajakah yang berhubungan dengan tingkat partisipasi anggota koperasi?

\section{Tujuan Penelitian}

Tujuan penelitian adalah untuk menganalisis:

1. Karakteristik pengurus, karyawan dan anggota Koperasi

2. Kinerja usaha dan tingkat partisipasi anggota

3. Faktor-faktor yang berhubungan dengan tingkat partisipasi anggota koperasi.

\section{METODE PENELITIAN}

\section{Metode, Tempat dan Waktu Penelitian}

Penelitian dilakukan dengan metode survei. Tempat penelitian adalah pada: KUD Tenera Jaya Di Desa Banjar Panjang Kecamatan Kerumutan Kabupaten Pelalawan dan Koperasi Bina Usaha Desa Benayah Kecamatan Pusako Kabupaten Siak Provinsi Riau. Penelitian dilakukan selama 6 bulan. Pada KUD Tenera Jaya Desa Banjar Panjang Kecamatan Kerumutan Kabupaten Pelalawan (bulan Mei sampai bulan Oktober 2018) dan pada Koperasi Bina Usaha di Desa Benayah Kecamatan Pusako Kabupaten Siak Provinsi Riau (bulan April 2019 sampai dengan bulan September 2019).

\section{Teknik Pengambilan Sampel}

Responden penelitian terdiri dari anggota, pengurus dan karyawan. Responden Pengurus dan Karyawan diambil secara sensus, yaitu masing-koperasi berjumlah 3 pengurus dan 3 karyawan. Responden anggota Koperasi Tenera Jaya diambil secara cluster Sampling berjumlah 44 orang dari 370 orang. Sampel anggota pada Koperasi Bina Usaha diambil secara stratified sampling yaitu 60 orang dari 210 orang.

\section{Teknik Pengumpulan Data}

Jenis data adalah data Primer dan data sekunder. Tehnik pengumpulan data melalui wawancara menggunakan instrument penelitian 
dan observasi. Data Primer meliputi: (1) Karakteristik Pengurus, Karyawan dan Anggota Koperasi, (2) Data Kinerja Usaha Koperasi dan (3) Data partisipasi anggota koperasi. Data Sekunder: Data gambaran umum daerah penelitian, data keuangan koperasi, keanggotaan koperasi, dan lain-lain.

\section{Teknik Analisis Data}

Karakteristik anggota, pengurus dan karyawan dianalisis secara statistic deskriptif. Analisis Kinerja Usaha terdiri dari analisis kinerja usaha secara kuantitatif (Nilai Manfaat Ekonomi Langsung analisis Efisiensi Ekonom) dan Kinerja usaha secara kualitatif (pengukuran skor indicator pada Tabel 2). Tingkat Partisipasi dianalisis secara kualitatif (pengukuran skor indicator pada Tabel 3.

Analisis kriteria efiseiensi ekonomi koperasi mengacu kepada Keputusan Menteri Negara Koperasi dan Usaha Kecil dan Menengah Republik Indonesia Tentang Pedoman Klarifikasi Koperasi Tahun 2009 (Tabel 1).

Tabel 1. Keputusan Mentri Negara Koperasi dan Usaha Kecil dan Menengah Republik Indonesia Tentang Pedoman Klarifikasi Koperasi Tahun 2009.

\begin{tabular}{lccrl}
\hline No & Jenis rasio & Standar $\%$ & Nilai & \multicolumn{1}{c}{ Keterangan } \\
\hline \multirow{4}{*}{1 Tingkat Perputaran Modal Usaha } & $\geq 3,5$ & 100 & Sangat baik \\
& $2,5 \mathrm{sd}<3,5$ & 70 & Baik \\
& $1,5 \mathrm{sd}<2,5$ & 50 & Cukup baik \\
& $1 \mathrm{sd}<1,5$ & 25 & Kurang baik \\
& $<1$ & 0 & Tidak baik \\
\hline \multirow{2}{*}{ Profit Margin } & $\geq 15$ & 100 & Sangat baik \\
& $10 \mathrm{sd}<15$ & 70 & Baik \\
& $5 \mathrm{sd}<10$ & 50 & Cukup baik \\
& $1 \mathrm{sd}<5$ & 25 & Kurang baik \\
& $<1$ & 0 & Tidak baik \\
\hline \multirow{2}{*}{ Rentabilitas Ekonomi } & $\geq 10$ & 100 & Baik \\
& $7,5-10$ & 70 & Cukup baik \\
& $5-7,5$ & 50 & Kurang baik \\
& 5 & 0 & Tidak baik \\
\hline \multirow{2}{*}{ Rentabilitas Modal Sendiri } & $\geq 21$ & 100 & Sangat baik \\
& $15 \mathrm{sd}<21$ & 70 & Baik \\
& $9 \mathrm{sd}<15$ & 50 & Cukup baik \\
& $1 \mathrm{sd}<9$ & 25 & Kurang baik \\
& $<5$ & 0 & Tidak baik \\
\hline \multirow{2}{*}{ Tingkat Perputaran Modal Kerja } & $2 \mathrm{kali}-3 \mathrm{kali}$ & 75 & Sangat baik \\
& $0 \mathrm{kali}-1 \mathrm{kali}$ & 50 & Cukup baik \\
& $<0 \mathrm{kali}$ & 0 & Kurang baik \\
\hline & & &
\end{tabular}


Tabel 2. Variabel dan Indikator Kinerja Koperasi

\begin{tabular}{|c|c|c|}
\hline No & Pertanyaan & Indikator \\
\hline \multirow[t]{3}{*}{1} & Kineria Organisasi & 1. Memiliki struktur organisasi \\
\hline & Koperasi & 2. Rutin mengadakan rapat akhir tahun (RAT) \\
\hline & & 3. Melakukan pembagian SHU \\
\hline \multirow{3}{*}{2} & Kinerja dalam Bidang & 1. Menyediakan usaha simpan pinjam untuk semua anggota koperasi \\
\hline & Usaha & 2. Melakukan jual beli TBS pada anggota koperasi \\
\hline & & 3. Menyediakan waserda untuk memenuhi kebutuhan anggota koperasi \\
\hline \multirow{4}{*}{3} & & 1. Koperasi memberikan pelayanan terbaik kepada anggota \\
\hline & Kinerja Dalam & 2. Pengurus koperasi sangat tanggap dalam membantu melakukan \\
\hline & Pelayanan & transaksi simpan pinjam \\
\hline & & $\begin{array}{l}\text { 3. Pengurus koperasi sangat cepat menanggapi masalah pada pelayanan } \\
\text { koperasi }\end{array}$ \\
\hline \multirow{3}{*}{4} & Kinerja Dalam & 1. Memiliki komunikasi yang baik dengan para anggota \\
\hline & Kepemimpinan & 2. Adil dan jujur dalam melayani para anggota \\
\hline & & $\begin{array}{l}\text { 3. Bertanggung jawab dalam menjalankan tugas dari masing-masing } \\
\text { jabatan }\end{array}$ \\
\hline
\end{tabular}

(Sumber: Modifikasi dari Teori dan Penelitian Terdahulu)

Tabel 3. Variabel dan Indikator Partisipasi Anggota

\begin{tabular}{|c|c|c|}
\hline No & Pertanyaan & Indikator \\
\hline \multirow[t]{3}{*}{1} & Partisipasi dalam & 1. Rutin menghadiri rapat akhir tahun (RAT) \\
\hline & Bidang Organisasi & 2. Ikut serta dalam menjalankan organisasi \\
\hline & & 3. Aktif dalam bermusyawarah atau memberi pendapat \\
\hline \multirow[t]{3}{*}{2} & Partisipasi dalam & 1. Membayar simpanan pokok \\
\hline & Bidang & 2. Memanfaatkan modal untuk berwirausaha \\
\hline & Permodalan & 3. Modal usaha berkembang sangat baik \\
\hline \multirow[t]{3}{*}{3} & Partisipasi & 1. Anggota Menjual TBS melalui koperasi \\
\hline & Terhadap Kegiatan & 2. Melakukan simpan pinjam pada koperasi \\
\hline & Koperasi & 3. Memanfaatkan waserda yang disediakan koperasi \\
\hline \multirow[t]{4}{*}{4} & Partisipasi dalam & 1. Hak untuk diberitahu mengenai hal yang berhubungan dengan \\
\hline & Hak dan & koperasi \\
\hline & Kewajiban & 2. Hak untuk memberi saran dan pendapat \\
\hline & Anggota Koperasi & 3. Kewajiban untuk memenuhi anggaran dasar \\
\hline
\end{tabular}

(Sumber: Modifikasi dari Teori dan Penelitian Terdahulu)

\section{HASIL DAN PEMBAHASAN}

\section{Karakteristik Pengurus, Karyawan dan Anggota Koperasi}

Hasil penelitian karakteristik pengurus, karyawan dan anggota koperasi adalah: Rataan umur pengurus 51 tahun, karyawan 35 tahun dan anggota 49,81 tahun. Semua masih termasuk umur produktif, namun untuk pengurus perlu regenerasi. Rata-rata tingkat pendidikan pengurus 10,5 tahun (tidak tamat
SLTA), karyawan 11,5 tahun (tamat SLTA) dan anggota 8,45 tahun (setara SLTP). Tingkat pendidikan pengurus,karyawan dan aggota koperasi tergolong rendah. Rata-rata pengalaman berusaha pengurus 10,06 tahun, karyawan 10,33 tahun, dan anggota 12,45 tahun. Rata-rata jumlah pendapatan dari kelapa sawit pengurus Rp 2,6 juta perbulan, karyawan Rp 2,28 jt perbulan dan anggota $\mathrm{Rp} 2,99$ jt perbulan. Jumlah tanggungan keluarga pengurus rata-rata 3 orang, karyawan 2 orang dan anggota 3 orang (Tabel 4) 
Tabel 4. Karakteristik Pengurus, Karyawan dan Anggota Koperasi

\begin{tabular}{|c|c|c|c|c|c|c|c|}
\hline \multirow[b]{2}{*}{ No } & \multirow[b]{2}{*}{ Karakteristik } & \multicolumn{2}{|c|}{ Pengurus } & \multicolumn{2}{|c|}{ Karyawan } & \multicolumn{2}{|c|}{ Anggota } \\
\hline & & $\begin{array}{r}\text { KUD } \\
\text { Tenera } \\
\text { Jaya }\end{array}$ & $\begin{array}{r}\text { Kop. Bina } \\
\text { Usaha }\end{array}$ & $\begin{array}{r}\text { KUD } \\
\text { Tenera } \\
\text { Jaya }\end{array}$ & $\begin{array}{r}\text { Kop. Bina } \\
\text { Usaha }\end{array}$ & $\begin{array}{r}\text { KUD } \\
\text { Tenera } \\
\text { Jaya }\end{array}$ & $\begin{array}{r}\text { Kop. Bina } \\
\text { Usaha }\end{array}$ \\
\hline 1 & Umur & 59,33 & 42,67 & 40,67 & 29,5 & 48,00 & 51,63 \\
\hline 2 & Pendidikan & 12 & 9 & 11 & 12 & 9 & 7,97 \\
\hline 3 & Pengalaman & 13,33 & 7 & 12 & 9 & 15 & 9,1 \\
\hline 4 & $\begin{array}{l}\text { Tanggungan } \\
\text { Keluarga } \\
\text { Pendapatan }\end{array}$ & 3 & 3 & 3 & 2 & 3 & 3 \\
\hline 5 & $\begin{array}{l}\text { Petani Kelapa } \\
\text { Sawit }\end{array}$ & 3.333 .000 & $2,066,666$ & 3.067 .000 & $1,500,000$ & 3.275 .000 & 2.703 .466 \\
\hline
\end{tabular}

\section{Tingkat Kinerja Usaha Koperasi}

Kinerja usaha koperasi dianalisis melaui Manfaat Ekonomi Langsung yang diterima anggota koperasi (Rupiah per tahun) dan efisiensi ekonomi koperasi. Manfaat Ekonomi langsung yang diterima anggota koperasi adalah terdiri dari: (1) Manfaat dari penjualan Tandan Buah Sawit segar yang dijual melalui koperasi, (2) Manfaat Pinjaman yang diperoleh dari koperasi dibandingkan dengan pinjaman di luar koperasi, dan (3) Manfaat yang diterima anggota koperasi dalam membeli herbisida dibandingkan harga di luar koperasi. Besarnya nilai manfaat tersebut per tahun disajikan pada Tabel 5.

Berdasarkan Tabel 5, Manfaat Ekonomi Langsung (MEL) Usaha KUD Tenera Jaya Tahun 2016-2017 mengalami peningkatan sebesar 20,85\% dari tahun 2016 sebesar Rp 276.552.017 dan menjadi Rp 349.384.046 pada tahun 2017. MEL TBS berjumlah Rp 298.101.257 pada tahun 2016 menjadi Rp 366.642.576 pada tahun 2017, MEL Pinjaman sebesar Rp -23.202.240 pada tahun 2016 menjadi Rp -19.538.530 pada tahun 2017, MEL Herbisida Rp 1.653.000 pada tahun 2016 menjadi Rp 2.280.000 pada tahun 2017 .

Tabel 5. Manfaat Ekonomi Langsung (MEL) Usaha KUD Tenera Jaya Tahun 2016-2017.

\begin{tabular}{|c|c|c|c|}
\hline No & Uraian & 2016 & 2017 \\
\hline 1 & MEL TBS (Rp) & 298.101 .257 & 366.642 .576 \\
\hline 2 & MEL Pinjaman (Rp) & $(23.202 .240)$ & $(19.538 .530)$ \\
\hline 3 & MEL Herbisida (Rp) & 1.653 .000 & 2.280 .000 \\
\hline & Jumlah & 276.552 .017 & 349.384 .046 \\
\hline
\end{tabular}

Analisis efisiensi ekonomi Koperasi dianalisis dari aspek: Rasio Tingkat Perputaran Modal Usaha, Profit Margin, Rentabilitas Ekonomi, Tingkat Perputaran Modal Kerja, dan Return On Working Capital. Hasil penelitian menunjukkan bahwa semua aspek dari efisiensi ekonomi tersebut termasuk kaetgori sangat baik. Artinya kinerja usaha KUD Tenera Jaya memberikan manfaat ekonomi kepada anggota dan efisien secara eonomi.

Tabel 6. Rasio Tingkat Perputaran Modal Usaha KUD Tenera Jaya Desa Banjar Panjang Kecamatan Kerumutan Kabupaten Pelalawan periode 2016-2017

\begin{tabular}{cccccc}
\hline Tahun & Penjualan $(\mathrm{Rp})$ & Modal Usaha $(\mathrm{Rp})$ & Rasio $(\%)$ & Standar $(\%)$ & Keterangan \\
\hline 2016 & 115.900 .000 & 658.097 .569 & 17,61 & $\geq 3,5$ & Sangat Baik \\
2017 & 129.284 .733 & 727.595 .753 & 17,77 & $\geq 3,5$ & Sangat Baik \\
\hline \multicolumn{7}{c}{ Rata-rata } & & 17,69 & $\geq 3,5$ & Sangat Baik \\
\hline
\end{tabular}

Profit Margin (PM) nilai masing-masing pada tahun 2016-2017 dapat dilihat pada Tabel 7. 
Tabel 7. Profit Margin KUD Tenera Jaya Desa Banjar Panjang Kecamatan Kerumutan Kabupaten Pelalawan periode 2016-2017

\begin{tabular}{|c|c|c|c|c|c|c|}
\hline Tahun & $\begin{array}{c}\text { SHU Sebelum } \\
\text { Pajak (Rp) }\end{array}$ & $\begin{array}{c}\text { Manfaat } \\
\text { Langsung (Rp) }\end{array}$ & $\begin{array}{l}\text { Penjualan } \\
\text { (Rp) }\end{array}$ & $\begin{array}{c}\text { Rasio } \\
(\%)\end{array}$ & $\begin{array}{c}\text { Standar } \\
(\%)\end{array}$ & Keterangan \\
\hline 2016 & 76.445 .385 & $67.271 .398,80$ & 115.900 .000 & 124,00 & $\geq 15$ & Sangat Baik \\
\hline 2017 & 73.077 .684 & $64.308 .361,92$ & 129.284 .733 & 106,27 & $\geq 15$ & Sangat Baik \\
\hline \multicolumn{4}{|c|}{ Rata-rata } & 115,13 & $\geq 15$ & Sangat Baik \\
\hline
\end{tabular}

Rentabilitas Ekonomi adalah rasio yang digunakan untuk mengukur kemampuan koperasi untuk menghasilkan laba selama periode tertentu dan dinyatakan dalam presentase. Hasil perhitungan rentabilitas ekonomi baik secara langsung maupun secara tidak langsung dapat dilihat pada Tabel 8 .

Tabel 8. Rentabilitas Ekonomi Secara Langsung KUD Tenera Jaya Desa Banjar Panjang Kecamatan Kerumutan Kabupaten Pelalawan Periode 2016-2017

\begin{tabular}{ccccccc}
\hline Tahun & $\begin{array}{c}\text { SHU } \\
\text { Sebelum } \\
\text { Pajak (Rp) }\end{array}$ & $\begin{array}{c}\text { Manfaat Langsung } \\
(\mathrm{Rp})\end{array}$ & Modal Usaha (Rp) & $\begin{array}{c}\text { Rasio } \\
(\%)\end{array}$ & $\begin{array}{c}\text { Standar } \\
(\%)\end{array}$ & Keterangan \\
\hline 2016 & 76.445 .385 & $67.271 .398,80$ & 658.097 .569 & 21,84 & $\geq 10$ & Sangat Baik \\
2017 & 73.077 .684 & $64.308 .361,92$ & 727.595 .753 & 18,88 & $\geq 10$ & Sangat Baik \\
\hline & Rata-rata & & 20,36 & $\geq 10$ & Sangat Baik \\
\hline
\end{tabular}

Tabel 9. Rentabilitas Ekonomi Secara Tidak Langsung KUD Tenera Jaya Desa Banjar PanjangKecamatan Kerumutan Kabupaten Pelalawan Periode 2016-2017.

\begin{tabular}{cccccc}
\hline Tahun & Profit Margin $(\%)$ & TPMU (\%) & Rasio $(\%)$ & Standar $(\%)$ & Keterangan \\
\hline 2016 & 124,00 & 17,61 & 21,84 & $\geq 10$ & Sangat Baik \\
2017 & 106,27 & 17,77 & 18,88 & $\geq 10$ & Sangat Baik \\
\hline \multicolumn{7}{r}{ Rata-rata } & & 20,36 & $\geq 10$ & Sangat Baik \\
\hline
\end{tabular}

Tabel 10. Rentabilitas Modal Sendiri KUD Tenera Jaya Desa Banjar Panjang Kecamatan Kerumutan Kabupaten Pelalawan Periode 2016-2017.

\begin{tabular}{|c|c|c|c|c|c|c|}
\hline Tahun & $\begin{array}{l}\text { SHU Setelah } \\
\text { Pajak (Rp) }\end{array}$ & $\begin{array}{c}\text { Manfaat } \\
\text { Langsung (Rp) }\end{array}$ & $\begin{array}{l}\text { Modal Usaha } \\
\text { (Rp) }\end{array}$ & $\begin{array}{c}\text { Rasio } \\
(\%)\end{array}$ & $\begin{array}{l}\text { Standar } \\
(\%)\end{array}$ & Keterangan \\
\hline 2016 & $67.271 .398,80$ & $67.271 .398,80$ & 658.097 .569 & 20,44 & $\geq 10$ & Sangat Baik \\
\hline 2017 & 64.308.361,92 & 64.308.361,92 & 727.595 .753 & 17,68 & $\geq 10$ & Sangat Baik \\
\hline \multicolumn{4}{|c|}{ Rata-rata } & 19,66 & $\geq 10$ & Sangat Baik \\
\hline
\end{tabular}

Tabel 11. Rasio Tingkat Perputaran Modal Kerja KUD Tenera Jaya Desa Banjar Panjang Kecamatan Kerumutan Kabupaten Pelalawan Periode 2016-2017.

\begin{tabular}{cccccc}
\hline Tahun & Penjualan (Rp) & Modal Kerja (Rp) & Rasio $(\%)$ & $\begin{array}{c}\text { Standar } \\
(\%)\end{array}$ & Keterangan \\
\hline 2016 & 115.900 .000 & 658.097 .569 & 0,18 & $>3$ & Cukup Baik \\
2017 & 129.284 .733 & 727.595 .753 & 0,18 & $>3$ & Cukup Baik \\
\hline Rata-rata & & 0,18 & $>3$ & Cukup Baik \\
\hline
\end{tabular}

Perputaran modal kerja adalah kemampuan modal kerja (neto) berputaran satu periode siklus kas dari perusahaan. Perputaran modal kerja dapat dihitung dengan membandingkan antara penjualan neto dan modal kerja. Nilai rasio tingkat perputaran modal kerja KUD Tenera Jaya dapat dilihat pada Tabel 11. Hal ini menunjukan bahwa tahun 2016 rasio tingkat perputaran modal usaha pada KUD Tenera Jaya sebesar 17,61 kali. Sedangkan pada tahun 2017 rasio tingkat perputaran modal usaha sebesar $17,77 \mathrm{kali}$, hal ini berarti Rp. 1,00 modal usaha berputar akan menghasilkan pendapatan atau laba sebesar Rp 1,77 Maka menunjukan bahwa tingkat 
perputaran modal usaha dalam keadaan cukup baik.

Hasil perhitungan Return On Working Capital KUD Tenera Jaya dapat dilihat pada Tabel 12. Berdasarkan Tabel 12, hasil perhitungan rasio profit margin KUD Tenera Jaya pada tahun 2016 sebesar 124,00.\% dan pada tahun 2017 sebesar 106,27\%. Hasil perhitungan rasio didapatkan nilai rata-rata profit margin sebesar $115,13 \%$. Ini berarti setiap Rp10,00 penjualan akan menghasilkan keuntungan sebesar Rp 11,513. Hal ini menunjukan bahwa koperasi mempunyai kemampuan yang baik dalam menghasilkan keuntungan dalam menghasilkan laba atau keuntungan sehingga koperasi dalam keadaan efisien.

Tabel 12. Rasio Return On Working Capital KUD Tenera Jaya Desa Banjar Panjang Kecamatn Kerumutan Kabupaten Pelalawan Periode 2016-2017.

\begin{tabular}{ccccc}
\hline Tahun & $\begin{array}{c}\text { SHU Sebelum Pajak } \\
(\mathrm{Rp})\end{array}$ & $\begin{array}{c}\text { Manfaat Langsung } \\
(\mathrm{Rp})\end{array}$ & $\begin{array}{c}\text { Modal Kerja Rata- } \\
\text { rata }\end{array}$ & Rasio (Kali) \\
\hline 2016 & 76.445 .385 & $67.271 .398,80$ & 131.619 .514 & 109,19 \\
2017 & 73.077 .684 & $64.308 .361,92$ & 145.519 .151 & 94,41 \\
\hline \multicolumn{5}{c}{ Rata-rata } \\
\hline
\end{tabular}

Tingkat kinerja usaha pada Koperasi Bina Usaha juga dianalisis melalui indicatorindikator secara kualitatif (kategori) berdasarkan persepsi atau penilaian dari anggota koperasi. Hasil penelitian disajikan pada Tabel 13.

Tabel 13. Penilaian Terhadap Variabel Kinerja pada Koperasi Bina Usaha

\begin{tabular}{|c|c|c|c|c|c|c|}
\hline \multirow[t]{2}{*}{ No } & Kinerja & \multicolumn{4}{|c|}{ Kategori Jawaban } & \multirow[b]{2}{*}{ SB } \\
\hline & Koperasi & STB & TB & $\mathrm{KB}$ & B & \\
\hline 1 & $\begin{array}{l}\text { Kinerja dalam } \\
\text { Organisasi } \\
\text { Koperasi }\end{array}$ & - & - & $2(3.33 \%)$ & $58(96.67 \%)$ & - \\
\hline 2 & $\begin{array}{l}\text { Kinerja dalam } \\
\text { Bidang Usaha }\end{array}$ & - & - & $9(15 \%)$ & $49(81.67 \%)$ & $2(3.33 \%)$ \\
\hline 3 & $\begin{array}{l}\text { Kinerja dalam } \\
\text { Pelayanan }\end{array}$ & - & - & $7(11.67 \%)$ & $53(88.33 \%)$ & - \\
\hline 4 & $\begin{array}{l}\text { Kinerja dalam } \\
\text { Kepemimpinan }\end{array}$ & - & - & $1(1.67 \%)$ & $59(98.33 \%)$ & - \\
\hline & Keseluruhan & - & - & $1(1.675)$ & $58(96.66 \%)$ & $1(1.67 \%)$ \\
\hline
\end{tabular}

Berdasarkan Tabel 13, kinerja usaha Koperasi Bina Usaha yang meliputi aspek: Kinerja usaha dalam organisasi, dalam Bidang Usaha, Kinerja dalam pelayanan dan kinerja dalam kepemimpinan secara keseluruhan 96,66 persen dipersepsikan baik oleh anggota koperasi.

\section{Tingkat Partisipasi Anggota Koperasi}

Tingkat partisipasi anggota KUD pada ke dua koperasi secara keseluruhan termasuk kategori baik. Hasil penelitian disajikan pada Tabel 14 dan 15.
Faktor-faktor yang Berhubungan dengan Tingkat Partisipasi Anggota Koperasi

Faktor-faktor yang berhubungan dengan tingkat partisipasi anggota koperasi yang dianalisis adalah factor karakteristik anggota koperasi (meliputi umur, tingkat Pendidikan, pengalaman menjadi anggota koperasi dan pendapatan dari usaha perkebunan kelapa sawit) dan kinerja usah akoperasi. 
Tabel 14. Partisipasi Anggota Koperasi pada Koperasi Bina Usaha di Desa Benayah Kecamatan Pusako Kabupaten Siak, Provinsi Riau

\begin{tabular}{rlccccc}
\hline No & Partisipasi & \multicolumn{5}{c}{ Kategori Jawaban Anggota } \\
& Anggota & STB & TB & KB & B & SB \\
\hline 1 & Partisipasi dalam & - & - & $12(20 \%)$ & $28(46.67 \%)$ & $20(33.33 \%)$ \\
& $\begin{array}{l}\text { Bidang Organisasi } \\
2\end{array}$ & & & & & \\
& $\begin{array}{l}\text { Partisipasi dalam } \\
\text { Bidang Permodalan }\end{array}$ & & & - & $58(96.67 \%)$ & $2(3.33 \%)$ \\
3 & $\begin{array}{l}\text { Partisipasi dalam } \\
\text { Kegiatan Koperasi }\end{array}$ & - & - & $2(3.33 \%)$ & $8(13.34 \%)$ & $50(83.33 \%)$ \\
4 & $\begin{array}{l}\text { Partisipasi dalam } \\
\text { Hak dan Kewajiban }\end{array}$ & - & - & - & - & $60(100 \%)$ \\
& Koperasi & & & & & \\
\hline Keseluruhan & - & - & - & $10(16.67)$ & $50(83.33 \%)$ \\
\hline
\end{tabular}

Tabel 15. Tingkat Partisipasi Anggota KUD Tenera Jaya Desa Banjar Panjang Kecamatan Kerumutan Kabupaten Pelalawan Provinsi Riau

\begin{tabular}{|c|c|c|c|c|c|c|}
\hline \multirow[t]{2}{*}{ No } & \multirow{2}{*}{$\frac{\text { Partisipasi }}{\text { Anggota }}$} & \multicolumn{4}{|c|}{ Kategori Jawaban } & \multirow[b]{2}{*}{ SB } \\
\hline & & STB & TB & $\mathrm{KB}$ & B & \\
\hline 1 & $\begin{array}{l}\text { Partisipasi dalam } \\
\text { pengambilan keputusan }\end{array}$ & - & - & - & $31(59,62)$ & $21(40,38)$ \\
\hline 2 & $\begin{array}{l}\text { pelaksanaan kegiatan dan } \\
\text { pelayanan koperasi }\end{array}$ & & & $3(5,77)$ & $10(19,23)$ & $39(75,00)$ \\
\hline 3 & $\begin{array}{l}\text { Partisipasi anggota dalam } \\
\text { evaluasi program koperasi }\end{array}$ & - & - & - & $13(25)$ & $39(75,00)$ \\
\hline \multirow[t]{3}{*}{4} & Partisipasi dalam & - & - & & & $44(84,62)$ \\
\hline & Hak dan Kewajiban & & & $2(3,85)$ & $6(11,54)$ & \\
\hline & Koperasi & & & & & \\
\hline \multicolumn{2}{|c|}{ Keseluruhan } & - & - & - & $11(21,15)$ & $41(78,85)$ \\
\hline
\end{tabular}

Tabel 16. Faktor-faktor yang Berhubungan dengan Tingkat Partisipasi Anggota Koperasi

\begin{tabular}{llcl}
\hline \multirow{2}{*}{ No } & \multicolumn{1}{c}{ Aspek } & $\begin{array}{l}\text { Koefisien } \\
\text { Korelasi Terhadap } \\
\text { Partisipasi } \\
\text { Anggota Koperasi }\end{array}$ & \multicolumn{1}{c}{ Keterangan } \\
\hline 1 & Umur & .246 & Hubungan Negatif, tidaksignifikan \\
2 & Pendidikan & -.081 & Hubungan Negatif, tidaksignifikan \\
3 & Pengalaman & $.394^{* *}$ & Hubungan positif, cukup erat signifikan \\
4 & Jumlah Tanggungan & $-.311^{*}$ & Hubungan Negatif, signifikan \\
5 & keluarga & .381 & Hubungan positif,tidak signifikan \\
6 & Kendapatan Sawit & $.906^{* *}$ & $\begin{array}{l}\text { Hubungan positif,sangat erat dan sangat } \\
\text { signifikan }\end{array}$ \\
\hline
\end{tabular}

Berdasarkan hasil penelitian pada Tabel 16, ternyata Faktor-faktor yang berhubungan signifikan dengan tingkat partisipasi petani adalah Kinerja Usaha Koperasi dan pengalaman menjadi anggota KUD. Sedangkan faktor2 karakteristik yang lain tidak berhubungan signifikan. Artinya, semakin baik kinerja usaha koperasi yang dirasakan anggota, maka semakin 
meningkat tingkat partisipasi anggota terhadap koperasi. Selain itu, semakin berpengalaman menjadi anggota koperasi semakin baik tingkat partisipasi anggota koperasi.

\section{KESIMPULAN DAN SARAN}

Kesimpulan dari penelitian adalah sebagai berikut:

1. Karakteristik pengurus, karyawan dan anggota koperasi adalah: Rataan umur pengurus 51 tahun, karyawan 35 tahun dan anggota 49,81 tahun. Semua masih termasuk umur produktif, namun untuk pengurus perlu regenerasi. Rata-rata tingkat pendidikan pengurus 10,5 tahun (tidak tamat SLTA), karyawan 11,5 tahun (tamat SLTA) dan anggota 8,45 tahun (setara SLTP). Tingkat pendidikan pengurus, karyawan dan aggota koperasi tergolong rendah. Rata-rata pengalaman berusaha pengurus 10,06 tahun, karyawan 10,33 tahun, dan anggota 12,45 tahun. Rata-rata jumlah pendapatan dari kelapa sawit pengurus $\mathrm{Rp}$ 2,6 juta perbulan, karyawan Rp 2,28 jt perbulan dan anggota Rp 2,99 jt perbulan. Jumlah tanggungan keluarga pengurus rata-rata 3 orang, karyawan 2 orang dan anggota 3 orang.

2. Nilai manfaat ekonomi langsung (MEL) dari unit usaha di KUD Tenera Jaya Desa Banja $r$ Panjang mengalami peningkatan, pada tahu n 2016 berjumlah Rp 276.552.017 menjadi Rp 349.384.046 pada tahun 2017.

3. Kinerja dari Koperasi Bina Usaha terdiri dari kinerja dalam organisasi koperasi, kinerja dalam bidang usaha, kinerja dalam bidang pelayanan, dan kinerja dalam kepemimpinan memperoleh nilai dengan kategori yang baik , secara keseluruhan hanya $1.67 \%$ yang memberikan penilaian yang kurang baik terhadap kinerja Koperasi Bina Usaha, akan tetapi hal tersebut tidak berpengaruh terhadap kinerja Koperasi Bina Usaha. Artikan bahwa secara keseluruhan kinerja di Koperasi Bina Usaha sudah baik. Sedangkan tingkat partisipasi anggota terdiri dari partisipasi dalam bidang organisasi, partisipasi dalam bidang permodalan, partisipasi dalam kegiatan koperasi dan partisipasi dalam hak dan kewajiban koperasi juga memperoleh nila dengan kategori yang baik. Artinya secara keseluruhan tingkat partisipasi anggota
Koperasi Bina Usaha sudah baik dan berhasil.

4. Faktor-faktor yang berhubungan signifikan dengan tingkat partisipasi petani adalah Kinerja Usaha Koperasi dan pengalaman menjadi anggota KUD. Sedangkan faktor2 karakteristik yang lain tidak berhubungan signifikan. Artinya, semakin baik kinerja usaha koperasi yang dirasakan anggota, maka semakin meningkat tingkat partisipasi anggota terhadap koperasi. Selain itu, semakin berpengalaman menjadi anggota koperasi semakin baik tingkat partisipasi anggota koperasi.

Berdasarkan hasil penelitian, dapat dirumuskansaran-saran sebagai berikut:

1. Diharapkan untuk pengurus koperasi dilakukan regenerasi, oleh karena pengurus yang ada sudah termasuk usia tua. Agar generasi muda dapat terjun berbisnis di dunia koperasi sebagai soko guru perekonomian Indonesia.

2. Kenyataan masih tingginya tingkat suku bunga koperasi, diharapkan pengelolaan usaha selain pinjaman dan keuangan koperasi lebih efisien, sehingga mampu memberikan pinjaman kepada anggota koperasi tanpa bunga (sesuai dengan perintah Allah mengharamkan praktek riba) dan mewujudkan peran koperasi menolong dan mensejahterakan anggota.

3. Meningkatkan efisiensi usaha dan keuangan koperasi melalui meningkatkan kompetensi manajerial dan profesionalisme dalam pengelolaan usaha dan keuangan sesuai Syariah Islam bagi pengurus dan karyawan koperasi.

\section{UCAPAN TERIMA KASIH}

Ucapan terimakasih disampaikan kepada Bapak/Ibu pengurus dan karyawan KUD Tenera Jaya Di Desa Banjar Panjang Kecamatan Kerumutan Kabupaten Pelalawan dan Koperasi Bina Usaha Desa Benayah Kecamatan Pusako Kabupaten Siak Provinsi Riau. Atas bantuan informasi, data dan kebersamaannya dalam penelitian yang telah kami lakukan. Ucapan yang sama juga disampaikan kepada Bapak/Ibu anggota ke dua koperasi tersebut, yang telah bersedia dan memberikan data dan meluangkan waktu ketika kami melakukan penelitian. Ucapan 
terimakasih juga disampaikan kepada Bapak Dekan dan pimpinan Fakultas Pertanian UIR atas dukunganyang diberikan kepada kami sehingga penelitian ini bias dipublikasikan.

\section{DAFTAR PUSTAKA}

Hanel, Alfred. 1989. Pokok-pokok Pikiran

Organisasi Koperasi dan Kebijakan.

Pengembangan di

Negara-negara Berkembang.

UNPAD. Bandung.

Hendar. 2010. Manajemen Perusahaan

Koperasi. Erlangga. Jakarta.

Kementerian Negara Koperasi dan Usaha Kecil dan Menengah Republik Indonesia. 2009. Pedoman Klasifikasi Koperasi Indonesia. Jakarta.

Ketaren N. 2007. Faktor-Faktor yang Mempengaruhi Keberhasilan Koperasi Kredit Union dalam pemberdayaan Masyarakat. Jurnal Harmoni Sosial, 1 (3): 138-146.

Kusnadi dan Hendar. 2005. Ekonomi Koperasi. Untuk Perguruan Tinggi. Edisi Kedua. Fakultas Ekonomi. Universitas Indonesia. Jakarta. 
